\title{
Discussion on the Construction of Low Carbon Industrial Park
}

\author{
Jianfang Zong*, Liang Chen, Liang Sun, Huiting Guo
}

China National Institute of Standardization, No.4 Zhichun Road, Haidian District, Beijing, 100084

\begin{abstract}
The low carbon industrial park is the significant carrier of construction of low carbon cities and development of low carbon economy. Construction and development of low carbon industrial park has a significant meaning to realization China's overall low carbon transformation and ecological civilization. This paper elaborates the connotation and features and analyzes the construction background of low carbon industrial park, and also points out the necessity and significance of the construction of low carbon industrial park. Besides, this paper also provides the domestic and overseas construction experiences of low carbon industrial park, and provides some countermeasures and suggestions about the construction and development of low carbon industrial park.
\end{abstract}

\section{Introduction}

"Low-carbon" was a concept emerging in UK in 2003. Due to the increasingly aggravated impact of global climate change on human living environment, the lowcarbon development idea that is intended to reduce the carbon emissions and slow down the global climate change has been deep in the hearts of people in just a few short years, and gradually become an international trend. As the significant unit and implementation subject, the industrial park is the key to realizing global emission reduction and development of low carbon city and economy. The low carbon industrial park is the new model of industrial park development proposed by the developed countries to respond to global climate change, stressing to obtain the larger economic output with less greenhouse gas (GHG) emissions. The construction of low carbon industrial park is the critical method to solve many complicated issues that are closely related to economic development, which will become China's significant choice to cope with the global climate change and develop the low carbon economy. At present, it is becoming a new international trend, which affects the economic and social development progress of each country.

\section{CONNOTATION AND FEATURES OF LOW CARBON INDUSTRIAL PARK}

The connotation of low carbon industrial park: it refers to the industrial zone planed by the government in a centralized and uniform manner. It is intended to adhere to the people-oriented principle and give overall consideration for the carbon emissions and sustainable development, actively adopt the cleaner production technology, and greatly enhance the usage efficiency of raw materials and energy consumption. Besides, it is also

\footnotetext{
* Corresponding author: zongif@enis.gov.cn
}

intended to eliminate the environmental pollutants during the production process if possible; Reasonably plan, design and manage the regional landscape and ecological system, and make the formation of low carbon industrial cluster as the final development target.

In general, the low carbon industrial park shall have the comprehensive features at the following four aspects: With regard to the industrial development, it shall promote the low carbon cycle of material and energy among different industries. With regard to the inner production links of the industrial park, it shall pay attention to cleaner production, and construct the low power consumption energy system. With regard to the planning and construction of low carbon industrial park, it is intended to realize the intensive usage of land, reasonable structure of industrial function and good ecological environment, and establish the carbon sequestration ecological environment system within the industrial park. Finally, it is also required to perfect and improve the operation policy, low carbon planning, construction and management system within the low carbon industrial park [1].

An ideal low carbon industrial park shall have the following four major features: First, it is intended to realize the high-efficiency utilization of energy and resources. At present, it is required to promote the industrial transformation and upgrading within the industrial park, and suppress the excessive growth of high consumption industry. Besides, it is required to optimize the energy structure, greatly enhance the industrial performance, and adopt the distributed energy resources in the light of local conditions. It is encouraged to develop the recycling industry, energetically promote the water and electricity conservation technology, push the regional building energy saving certification system, and reduce the peak demand. Second, it is required to adopt the clean energy structure. It is required to reduce the utilization rate of fossil fuels, especially reducing the 
usage ratio of coal in the primary energy, promote the replacement of the oil to gas, and enhance the utilization rate of natural gas. Under the premise that the costs and returns will be checked, it is intended to gradually improve the usage ratio of renewable energy, and utilize the distributed renewable energy resources and microgrid system to effectively supplement the power grid. Third, it is required to adopt the city-industry integration policy. It is required to extend the industrial chain and make the tertiary service industry well developed. It is required to achieve the intensive use of land, perfect the incomplete life cycle support, establish the livable communities, ensure the hundred-year building quality, and construct the convenient integrated traffic system. Fourth, it is required to adapt to the climate change. It is required to strengthen the significant infrastructure, establish the green infrastructure, reduce the impermeable ground, and gradually expand the green land within the park zone.

\section{THE CONSTRUCTION BACKGROUND OF LOW CARBON INDUSTRIAL PARK}

\subsection{International background-global climate change threatens the requirements of GHG emissions reduction}

The climate change is an environmental problem, but after all, it is a development problem. In fact, the carbon emission permit centered climate game has already been converted to the competition for development space between countries. The climate change has already become the significant factor that will affect the economic and social sustainable development of each country. As the significant path to coordinate the social and economic development and respond to the climate change, "Low Carbon Development" has already become the consensus of more and more countries [2]. The international climate debate regarding the emission permit and development right has already hastened the delivery of low carbon economy concept.

Internationally, the GHG emissions caused by human activities are the major reasons of global climate change with the warming as the main features. It is indicated in "Stern review" that if the actions are not taken to reduce the GHG emissions, the concentration of GHG in the ambient air will be doubled as of 2035, as much as before industrialization, which will lead to the frequent occurrence of global extreme climate events, and seriously affect the economic and social development of human beings. Besides, it is stated in the UNEP's "The emissions gap report 2012" that the present global GHG emissions are about 50.1 Billion tons of carbon dioxide equivalent (the carbon dioxide emissions take account of the $76 \%$ of GHG emissions), achieving the target that the global warming by this century will be controlled at $2{ }^{\circ} \mathrm{C}$, and that the thresholds of global GHG emissions in 2020 and 2050 will be 44 Billion tons and 21 Billion tons respectively [3]. This shows that there is still a big gap of global GHG emissions reduction.
As a developing country, China is still not subject to the compulsory emissions reduction requirements. However, in recent years, with the rapid economic growth, China has already among the countries of largest GHG emissions worldwide. The voices that the international society requires China to be subject to the compulsory GHG emissions requirements are getting louder. Under the pressures from the international society, China not only actively explore the low carbon development path by pushing the energy conservation and emission reduction, cleaner production, recycling economy, and low carbon city construction and other actions in China, but also gradually demonstrate the active attitudes on the international stage. As a responsible power, China has already determined the target in 2009 that carbon dioxide emissions per Unit of GDP will be lowered by $40 \% \sim 45 \%$ as of 2020 , compared with that in 2005. The 18th National Congress of CPC also considers the low carbon development as the significant composition of China's ecologic civilization construction. At present, China is still at the middle-late phase of industrial development, while the industrial carbon emissions take the dominant position in China's total carbon emissions. The industrial park is the industrial cluster district, while the promotion of construction and development of low carbon industrial park will definitely become the significant contents of implementing the low carbon development idea and constructing the ecologic civilization in China [4].

\subsection{Domestic background-the contradiction between carrying capacity of the resource and environment and rapid economic growth becomes increasingly prominent}

Due to the technical level, development method and other reasons, behind China's rapid economic growth is the lower resources production rate and higher pollution emission intensity. Meanwhile, the energy consumption also rapidly increases [5]. The energy consumption per unit of GDP in China is 11.5 times of that in Japan, 4.3 times of that in USA, and 7.7 times of that in German and France. Compared with the developed countries, China's waste water discharge amount per unit of GDP is 4 times higher than them, while the solid wastes per unit of industrial output value is 10 times higher than them. In 2012, China's total energy consumption has already reached 3.62 Billion tons of standard coal, while the coal consumption reached 2.44 Billion tons, taking account of $50.2 \%$ coal consumption in the world. The large quantity of energy consumption leads to the continuous increase of China's carbon emissions. It is stated in the IEA study that the carbon emissions caused due to fuel combustion in China (including Hong Kong) reached 7.2 Billion tons in 2010, taking account of $23.8 \%$ of the global carbon emissions and 3 times higher than that in 1990, which is much higher than the world's average increase level of 0.44 [6]. This also affects China's international image to a certain degree. The rapid economic growth and lower resources production rate leads to the enormous resources and energy 
consumption, and continuously rising of China's energy consumption proportion worldwide. The contradiction between China's economic development and resource and environmental constraints have become increasingly prominant. If the present resources consumption rate and pollutant emission level will continuously be maintained, it will cause the permanent damage to the environment, and threaten China's long-term stability and stable development. Therefore, it has already become the inevitable course of China's economic development by developing the low carbon economy and reducing the material consumption and pollutant emissions.

\subsection{The sustainable development requirements of industrial park-low carbon industrial park is the park transformation and upgrading direction}

As the material space, the industrial park accumulates all types of production and creation activities and carries out all types of material and energy exchange. Therefore, the development of low carbon economy will have a significant impact upon the climate and environment. With the requirements of carbon dioxide emissions reduction, the development of industrial park will be affected to a certain degree. Therefore, how to reduce the carbon emissions of per unit of economic scale and also maintain the sustainability of industrial park construction and development, will be the significant driving force of low carbon city construction and low carbon economic development, and the key scheme to treat the global climate change. Therefore, low carbon industrial park will lead the new direction of park construction and development in future.

\section{NECESSITY AND SIGNIFICANCE OF LOW CARBON INDUSTRIAL PARK CONSTRUCTION}

The low carbon industrial park is established as per the theory of circular economy and principle of industrial ecology, stressing the symbiotic development of economic, environmental and social functions.

The construction of low carbon industrial park will strengthen the resources usage reduction, resources recycling and reclamation, and waste resources, and other measures taken by the enterprises, which will greatly enhance the utilization efficiency of resources. Meanwhile, the objective that the resources will be rationally utilized can be achieved through the cluster development of geographically adjacent enterprises, mutual utilization of wastes, and recycling of materials and energy. Therefore, the construction of low carbon industrial park is the realistic choice of rational utilization of resources and enhancement of the resources utilization efficiency. The low carbon industrial park will focus on establishing and arranging the enterprises in light of the symbiotic relationship of enterprises, form the integrated utilization of resources and environmental protection, and produce the better ecologic, economic and social benefits, so as to transform the existing industrial zone and increase the agglomeration economic effects.

The construction of low carbon industrial park and application of low carbon theory can provide the enterprises within the park with the strong cost advantage and premium advantage, so as to create the new economic growth point. The low carbon industrial park stresses to reduce the production cost and enhance the efficiency by enhancing the utilization efficiency of materials and energy, and reusing and recycling the wastes, so as to avoid the occurrence of illegal acts, and also enable the enterprises within the park to produce the more competitive products. Besides, some fundamental services can be shared among enterprises within the park to enable them to gain more economic benefits through cooperation. Such economic benefits gained by the involved enterprises will also add the value of property assets within the industrial park, and bring new incomes for the administrative department within the park. The enterprises within the park will be mutually connected through the ecologic chain, while their products and production processes will adhere to the environmental protection principle. Therefore, they can gain the premium benefits due to their special positions. Besides, the newly built low carbon industrial park can also obviously increase the market competitiveness.

Besides the economic benefits, the construction of low carbon industrial park can also have the obvious environmental and social benefits. The enterprises within the park can reduce many pollution sources and waste sources, and lower the demands and consumptions upon the natural resources with the more innovative cleaner production methods. It is intended to absorb the enterprises with better benefits to join through the enhanced economic benefits, and provide the good entrepreneurial environment and places for the new enterprises and local enterprises, so as to become the base of community economic development. Meanwhile, due to the participation of more enterprises, it also brings more jobs for the community. Besides, the local enterprises can find more service clients and buyers from the new enterprises within the park, so as to add more benefits. Besides, it is also required to gradually improve the air, soil and water quality within the park and greatly reduce the waste emissions, so as to form the more attractive park in general.

The guidelines for the construction of low carbon industrial park are to stick to the guideline of scientific outlook on development, and guidelines of peopleoriented and overall development. Besides, it is required to use the low carbon economy, circular economy, industrial ecology and other relevant knowledge as the theoretical support, use the low carbon industrial park construction as the carrier, use the transformation of development method. And promoting the better and faster economic development as the core, and focusing on reshaping the support of natural resources and improving the carrying capacity of ecological environment as the ket point, technological upgrading and introducing the new and abandoning the old as the method, to make the general layout, adjust according to the local conditions, make the long-term plan, make the 
phased construction, and make the gradual execution. In this manner, the planning and construction of low carbon industrial park will have the forward-looking, adaptability, and advancement, while it is also required to strive to build the horticulture, ecological and low carbon modern industrial park.

The construction ideas of low carbon industrial park are to realize the energy structure adjustment of low carbon industrial park with the low carbon energy method, optimize the industrial structure of low carbon industrial park with the low carbon industry method, demonstrate the essence of circular economy within the low carbon industrial park with the low carbon production method, and optimize the ecological environment within the low carbon industrial park with the low carbon emissions method. Besides, it is also required to guide the low carbon consumption within the low carbon industrial park with the low carbon idea, construct the technical innovation system within the low carbon industrial park with the low carbon technology, and safeguard the construction practice of low carbon industrial park with the policy, laws and regulations system.

\section{DOMESTIC AND OVERSEAS LOW CARBON PARK CONSTRUCTION EXPERIENCES}

The low carbon industrial park is the significant carrier of the modern industrial system featured in strong innovative capacity, excellent quality service, close cooperation and friendly environment. In August, 2015, the pilot implementation schemes of 39 national low carbon industrial park were formally approved by Ministry of Industry and Information Technology. The development of domestic low carbon industrial park not only has some similarities, but also has their own features. Most industrial parks belong to the significant composition of industrial base, provided with definite planning direction and multi-policy supports, located in the new urban district, and belong to the new economic growth point [7].

The overseas industrial park construction will mainly emphasize on the selection of leading industry, the perfection of relevant policy and regulation system, the infrastructure construction, the integration of city and low carbon industrial development, and etc. For instance, the Danish Kalundborg Eco-Industrial Park is the most typical representative of industrial ecological system operation worldwide, and centered around four enterprises, namely, the power plant, refinery, pharmaceutical factory, and gypsum board plant. In institutional arrangements, the government will compulsorily enforce the high charge policy upon the pollutant emissions, which have a strong external impact, while the government also provides the benefit incentives to the pollutant emissions reductions. Such four enterprises will mutually use the wastes or byproducts as the production raw materials and establish the industrial amphitrophy and metabolic ecological chain relationship, which not only reduces the cost and forms the objective economic benefits, but also realizes the zero-pollution and low emissions within the park zone. Japanese Kitakyushu Eco-city adopts the steel, chemical engineering, mechanical engineering, ceramics, information related industry and others as the primary industry. The government establishes the eco-industrial park compensation system, enforces a series of measures, such as concluding an agreement on the prevention of public hazards, providing the pollution monitoring center, and establishing the sewage treatment works, constructs the "Kitakyushu science and research park", and form the production, science and research integrated park management and operation model.

During the construction process, the low carbon park shall draw lessons from the construction experiences of domestic and overseas low carbon industrial park, integrate the low carbon development idea into the integrated planning, construction and development process of industrial park, and lead the industrial low carbon development with the low carbon demonstration of the industrial park. Besides, it is also required to properly plan the industrial park and select the appropriate leading industries. When the low carbon planning is made for the industrial park, it shall be based on the positioning of the industrial base that the industrial park belongs to, properly plan the industrial direction, collectively consider the recycling economic model among enterprises, and the integration model between cities and low carbon industries, and organic conformity of three major functions, namely, production, living and ecology functions.

It is required to strengthen the organizational leadership and implement the policy guarantee. It is required to set up the special work leading group, to make the overall planning and coordination of the major problems encountered during the low carbon transformation of the industrial park. And properly carry out the docking works, promote the interaction mechanism between departments, develop and promote the work plan, break down and implement the targets and tasks. Meanwhile, it is also required to develop and implement "carbon screening" mechanism for the enrolled enterprises, the energy conservation and carbon reduction evaluation and regulation mechanism of significant enterprises, and other relevant policies, establish the industrial park pilot special funds, and give the full support with regard to the application and demonstration, industrial cultivation, talent introduction, and etc.

It is required to perfect the technical support system and emphasize on the scientific research and talent cultivation. It is necessary to rely on the specialty industries within the park, and select the key industries to carry out the targeted promotion activities of low carbon technology and products. It is required to strengthen the low carbon international cooperation, strengthen the technical innovation, and promote the technical development and application. Besides, it is also required to develop and implement the talent policies, actively introduce the domestic and overseas leading enterprises, high-end talents, and scientific research institutions, strengthen the low carbon discipline 
construction in local vocational colleges, and cultivate the relevant professional talents.

Besides, it is required to enhance the carbon management capacity and transform the governmental management method. The industrial park construction shall take the local government as the main body, forming the "government, industry and academy integrated" park management and operation model, where the government, enterprises, research institutions and the public will jointly participate, while the enterprises will carry out the strong cooperation with research institutions and government. Meanwhile, it is also required to establish the carbon emissions information management platform, to provide the information support to the park carbon management and enhance the governmental carbon management efficiency upon the park.

\section{COUNTERMEASURES AND SUGGESTIONS FOR DEVELOPMENT OF LOW CARBON INDUSTRIAL PARK}

As a new type of industrial cluster, the low carbon industrial park can realize the social and economic sustainable development with less GHG emissions. It is especially necessary to carry out the energy conservation and emissions reduction in the industrial, building, transportation and other fields, reduce the total coal consumption, enhance the proportion of cleaner energy, and lead the public low carbon life. Besides, the low carbon industrial park will take a great function in reducing the fog and haze pollution [8].

The low carbon industrial park has an enormous development potential and efficiency. According to estimates, in a case study of 341 national development zones, if the greening rate will be enhanced by $5 \%$, 5.05 16.5 Million tons of carbon sink will be added. In case that the electricity consumption per unit area of public buildings will be decreased by 1 kilowatt hour, the emission reduction potential may also reach tens of millions of carbon dioxide. Through the reduction of Energy Consumption per unit of industrial-added value, during the "Twelfth five-year plan" period, the low carbon industrial park can help the industrial departments to reduce the carbon dioxide emissions by $41 \%$ and above. Compared with the traditional petroleum-based fuel car, the new-energy vehicles may reduce the carbon dioxide emissions by $25 \%$ and above. Besides, if the green travel proportion of the personnel within the low carbon industrial park may be increased, at least 5 million tons of carbon dioxide emissions may be reduced. In view of the foregoing, the following countermeasure and suggestions are given for the development of low carbon industrial park:

\subsection{The scientific planning shall be made to promote the construction practice of low carbon industrial park}

In order to effectively promote the construction practice of low carbon industrial park, it is necessary to scientifically plan the low carbon industrial park. As the significant unit of low carbon city development, the low carbon industrial park shall combine its planning with the entire city planning, becoming the significant composition part of the city planning. Besides, it shall also properly solve the business, life, education, medical care and other issues of low carbon industrial park, so as to accumulate the business atmosphere and enhance the popularity, making the low carbon industrial park become the pilot and demonstration area of the low carbon cities. Combining with China's existing urban planning preparation system, the low carbon industrial park planning may adopt the following three preparation systems: First, the low carbon industrial park planned beyond the existing park planning preparation system will be deemed as a new type of planning. Second, it will be deemed as the composition part of the existing park planning, and then be prepared and incorporated into the existing park planning system in the form of special planning or independent chapters. Third, the low carbon idea will be integrated into the existing park planning preparation system, realizing the low carbon target in all types of park planning contents, and implementing the low carbon target into the land layout, traffic model, industrial development and facility construction. In the long run, it is the main direction to integrate the low carbon idea into the park planning preparation system, which is also one of the significant aspects of its own development innovation of park planning.

The planning of low carbon industrial park must consider the impacts of economy, society, time and other factors upon the construction and development of low carbon industrial park, while the strategies, policies and regulations that are applicable to the park development shall be developed accordingly. Finally, it is required to implement the aforesaid and make them have the operability. The low carbon industrial park planning shall be considered as a process. Please neither desire that there is an ideal planning which can solve all problems once for all, nor expect that one planning can be completely and fully enforced. Therefore, the dynamic planning management model is a significant concept that is suitable to the development of China's low carbon industrial park. The low carbon industrial park planning may be divided into four interacted time span, while the longer time span will restrict the development of shorter time span. Meanwhile, the variation accumulation of shorter time span will form the dynamic evolution of longer time span. The low carbon industrial park planning may be divided into four gradually expanded levels, namely, forming the "enterprise-industry-society-ecology" whole spatial structure.

\subsection{Strengthening the innovation of scientific and technical mechanism, and building the low carbon technical innovation system}

The low carbon technology is not only the key to enhancing the future economic and social integrated competitiveness of the industrial park, but also is the 
means to abandon the high carbon development old path and old high carbon technical model of the park, and to realize the economic great-leap-forward development of the park. Therefore, the acceleration of low carbon technology development pace, is not only the strategic requirements of low carbon economic development of the park, but also is the realistic requirements of park social and economic development. At present, China has the following two methods to obtain the low carbon technology:

On one hand, we can introduce the mature technology of developed countries through the CDM, the advantage of which is lower cost. However, generally, we cannot obtain the overseas core technology, because the developed countries are worried about that the transfer of advanced technology will affect the international competitiveness of its own industries and products. Obviously, it is very hard to comprehensively promote the technical progress of China's low carbon industrial park.

On the other hand, we can carry out the independent research and development, namely, emphasize on the low carbon technology that can receive the larger efficiency in the short and middle term via the original innovation and integrated innovation, especially the new technologies that are intended to reduce the energy consumption of heavy and chemical industries, and then establish our own low carbon technology innovation system. From the connotation perspective, we shall adopt the following measures: First, it is required to increase the scientific and technical inputs, enhance the independent innovation capacity, and emphasize on the medium-long term strategic technology reserve. Second, it is required to integrate the existing low carbon technology on the market, and accelerate the transformation and application of technical and scientific achievements. Third, it is required to strengthen the R \& $\mathrm{D}$ of low carbon technology, and greatly develop the low carbon technology and products, such as solar power, biomass energy, wind energy, ocean energy and geothermal energy utilization technology, collection and storage technology of carbon dioxide, and etc. Fourth, it is required to accelerate the development utilization of nuclear energy, hydroelectric and other low carbon featured energies, coordinate and promote the technical upgrading of traditional industries and pollution emissions reduction, and continuously enhance the carbon sink functions of ecological system. Fifth, it is required to rely on the existing new energy technical innovation and industrial development platform, strengthen the international exchange and cooperation, and promote the technical transfer from developed countries [9].

\subsection{Establishing the evaluation index system for low carbon industrial park and guiding scientific development of the low carbon industrial park}

As an emerging concept, the low carbon industrial park lacks of the precise definition and relevant evaluation standards on the operation level. During its construction and development process, the deviation and even departure will easily arise. Therefore, it is required to carry out the research on evaluation index system for the low carbon industrial park, propose the construction standards and relevant specifications and policies at the earliest, and guide the construction and development of domestic low carbon industrial parks. Low carbon industrial park is a complicated system involving the economy, environment, society and many other levels, while it is hard to comprehensively and objectively reflect the construction and development level of low carbon industrial park with one or some indicators. Therefore, it is required to carry out the integrated evaluation from variable sides and levels as per the features of low carbon industrial park. For instance, the evaluation may be made by adopting the economic development, low carbon industry, low carbon technology, energy conservation and emissions, management system, and other indicators. The estimation-matrix method may be adopted to determine the index weight at all levels, which must be made in combination with the development stage and present development goals of low carbon industrial park, without sameness.

\subsection{Accelerating the system and mechanism innovation, and establishing the low carbon economic development system}

During the process of low carbon economic development, some developed countries enhanced the market regulation force, and gradually established a set of social system to encourage the low carbon economic development. During the construction and development process of low carbon industrial park, China shall also accelerate the system and mechanism innovation, and promote the construction and development of low carbon industrial park. First, it shall establish the price signal guidance mechanism of energy, resources and environmental products and services. Second, it shall establish the responsibility extension mechanism of Polluter Pays Principle. Third, it shall establish the standard system and third-party monitoring mechanism of energy resources consumption and pollutant emissions. Fourth, it is required to develop the emission limit system and emission permit trading mechanism. Fifth, it shall establish the technical access permit mechanism. Sixth, it shall establish the professional operation mechanism of energy conservation and environmental protection service enterprises.

\section{CONCLUSION}

Unlike developed countries, China is still in the middle and late stage of industrialization in general. Industry, especially heavy industry, still occupies a considerable proportion in the industrial structure. The industrialization stage determines that the low-carbon construction and transformation of industrial parks should be an important part of China's low-carbon 
development. The characteristics of diversified and differentiated industrial park in China determines that it cannot draw lessons from the developed countries with the experience of letting eco-industrial park construction drive the development of low carbon industrial park, and also cannot copy the same development pattern, but it must combine industrial park's own resources endowment, geographical environment, the stages of development aimed at building suitable mode of low carbon development. At present, the construction and development of low carbon industrial park both in our country and the world is still a new topic. Its connotation and development mode still needs further research and discussion, so as to provide theoretical support for more parks to transform to the high efficiency, low energy consumption, low carbon emissions model.

\section{References}

1. HONG Xiao, QIAN Zhonghao, On the Construction and Development of Low-carbon Parks-A case of Wujin High-tech Zone: Journal of Yangzhou University (Humanities and Social Sciences), 2011, 15 (6): 40-45

2. CHEN Ying, Accelerating the Green and LowCarbon Development, and Promoting the Ecological Civilization Construction: Environmental Protection, 2012 (23): 29-31

3. UNEP, The emissions Gap Report 2012[R], Nairobi: UNEP, 2012

4. ZHU Tan, FENG Yu, JI Yijun, LI Posong, Exploration on the Promotion Path of China's Low Carbon Industrial Park Construction and Development: Environmental Protection, 2014, 42 (2): 43-45

5. WANG Xian'en, LI Dufeng, ZHAO Wenjin, Strengthening the Energy Consumption Control and Promoting the Pollutants Emissions Reduction: Environmental Protection, 2013 (08): 29-31

6. IEA, $\mathrm{CO} 2$ emission from fuel combustion highlights, 2012[EB/OL], http://www.iea.org/publications/freepublications/pu blication/CO2emissionfromfuelcombustionHIGHLI GHTMarch2013.pdf

7. WEI Danqing, Inspirations of Domestic and Overseas Low Carbon Park Construction Experiences: Zhejiang Economy, 2016(10): 44

8. Transformation of China Industrial Development Zones: Towards a Low Carbon Future, 2013

9. LI Posong, FENG Yu, WANG Tiantian, Low Carbon Industrial Park Practice and Development Model Selection in China: Ecological Economy, 2014, 30(2): 143-147 